\title{
RESISTÊNCIA DE ESPÉCIES DE CANDIDA ISOLADAS DE LEITE PROVENIENTE DE MASTITE BOVINA À PASTEURIZAÇÃO E FERVURA
}

\author{
RESISTANCE OF CANDIDA SPECIES ISOLATED FROM MILK FROM BOVINE MASTITIS \\ TO PASTEURIZATION AND BOILING
}

L. C. AgOStinho SARTORI ${ }^{1}$, R. C.SANTOS ${ }^{1}$, J. M. MARIN ${ }^{2 *}$

\begin{abstract}
RESUMO
Este trabalho teve como objetivo a avaliação da resistência a pasteurização e a fervura de culturas do gênero Candida isoladas de leite bovino. Foram obtidos 45 isolados de Candida em leite provenientes de vacas leiteiras acometidas de mastite clínica ou sub-clínica em quatro estados brasileiros. As culturas foram submetidas a diferentes tratamentos térmicos, pasteurização rápida $\left(72-75^{\circ} \mathrm{C} / 20 \mathrm{seg}\right)$, pasteurização lenta $\left(62-65^{\circ} \mathrm{C} / 30 \mathrm{~min}\right)$, e fervura $\left(100^{\circ} \mathrm{C} / 1-3 \mathrm{seg}\right)$. A pasteurização rápida foi o procedimento no qual houve maior índice de resistência da levedura $(64,4 \%)$, seguida pela fervura $(15,5 \%)$ e pela pasteurização lenta $(6,6 \%)$. A persistência de diferentes espécies de Candida em leite submetido à pasteurização e a fervura, pode representar um risco ao consumidor, especialmente aos indivíduos imunocomprometidos, crianças e pessoas idosas.
\end{abstract}

PALAVRAS-CHAVE: Mastite bovina. Leite. Tratamento térmico. Levedura. Candida.

\section{SUMMARY}

The objective of this study was to evaluate the resistance of Candida species isolated from bovine milk to pasteurization and boiling. A total of 45 Candida isolates were obtained from mastitic milk of dairy cows with clinical or subclinical mastitis from four Brazilian States. The isolates were submitted to different thermal treatments, fast pasteurization (72$\left.75^{\circ} \mathrm{C} / 20 \mathrm{sec}\right)$, slow pasteurization $\left(62-65^{\circ} \mathrm{C} / 30 \mathrm{~min}\right)$ and boiling $\left(100^{\circ} \mathrm{C} / 1-3 \mathrm{sec}\right)$. Fast pasteurization was the procedure in which there was a higher resistance of yeast (64.4\%), followed by boiling (15.5\%) and slow pasteurization (6.6\%). Care should be taken regarding the possibility of Candida strains persistence in pasteurized and boiled milk, which can represent a risk to consumers especially to immuno-compromised individuals, children and elderly people.

KEY-WORDS: Bovine mastitis. Milk. Thermal treatment. Yeast. Candida.

\footnotetext{
${ }^{1}$ Pós graduadas do Programa de Microbiologia Agropecuária, Faculdade de Ciências Agrárias e Veterinárias, Universidade Julio de Mesquita (UNESP) - Câmpus de Jaboticabal, SP, Brasil.

${ }^{2}$ Professor Associado do Departamento de Morfologia, Fisiologia e Patologia Básica, FORP, Universidade de São Paulo (USP) Campus Ribeirão Preto, SP, Brasil. *Endereço para correspondência: José Moacir Marin, Departamento de Morfologia, Fisiologia e Patologia Básica, FORP, Universidade de São Paulo, Campus Ribeirão Preto, Avenida do Café s/n, Ribeirão Preto, São Paulo, Brasil, 14040-904. e-mail: jmmarin@ forp.usp.br
} 


\section{INTRODUÇÃO}

A mastite é definida como uma inflamação da glândula mamária, geralmente como conseqüência de infecção microbiana, e continua a ser a doença mais freqüente e dispendiosa em vacas leiteiras (SEKER, 2010). Mais de 150 diferentes microrganismos têm sido identificados como agentes etiológicos da mastite (WATTS, 1988; BRADLEY, 2002). Além dos agentes bacterianos, outros grupos de microrganismos como os fungos podem causar o processo inflamatório (WATTS, 1988; KRUKOWSKI et al., 2006).

Os fungos são componentes naturais da microbiota do solo e podem colonizar a pele do úbere em pequeno número. Eles são considerados oportunistas e produzem doença quando os mecanismos de defesa naturais estão reduzidos (KIRK \& BARLETT, 1986). As espécies de Candida são os organismos mais freqüentemente isolados entre os agentes etiológicos da mastite micótica em glândulas mamárias infectadas (SPANAMBERG et al., 2009, ZHOU et al, 2013.).

Existem relatos na literatura sobre a ocorrência de leveduras em leite e queijo de bovinos (CORBO et al., 2001). A presença de microrganismos no leite, muitos dos quais responsáveis por zoonoses, representa um fator que compromete a sua qualidade e segurança. Portanto, com o objetivo de reduzir o teor microbiano no leite, bem como a eliminação de microorganismos potencialmente perigosos para os seres humanos, a pasteurização é o procedimento mais utilizado (KOUSTA et al, 2010). O objetivo deste estudo foi avaliar a resistência de espécies de Candida isoladas de leite proveniente de bovinos com mastite frente à diferentes tratamentos térmicos.

\section{MATERIAL E MÉTODOS}

\section{Animais amostrados}

O estudo foi conduzido com vacas de propriedades leiteiras, mantidas sob o sistema intensivo de criação, distribuídas em quatro estados brasileiros, São Paulo (6 fazendas), Paraná (14 fazendas), Santa Catarina ( 7 fazendas) e Rio Grande do Sul (14 fazendas). Os rebanhos analisados eram constituídos por animais de diferentes raças, idades e em diferentes fases de lactação.

\section{Critérios para a classificação em mastite clínica ou sub-clínica}

A mastite clinica foi caracterizada por sinais clínicos e/ou secreção de leite anormal detectada pelo teste da caneca de fundo preto. A mastite sub-clínica foi identificada pelo CMT (California Mastitis Test) convencional.

\section{Amostras de leite}

Quatrocentos e vinte e oito amostras de leite de quartos com mastite clínica ou sub-clínica foram coletados no período de Fevereiro a Dezembro de 2009. As amostras de leite $(10 \mathrm{~mL})$ foram sempre coletadas assepticamente em frascos de vidro esterilizados após a desinfecção dos tetos com álcool a $70 \%$. Os três primeiros jatos de leite foram descartados, e em seguida o quarto jato foi coletado e mantido a uma temperatura de $4^{\circ} \mathrm{C}$ até processamento no laboratório. Alíquotas de $0,1 \mathrm{~mL}$ de amostras de leite foram semeadas em ágar Sabouraud Dextrose (SDA, Oxoid) suplementado com cloranfenicol $(400 \mathrm{mg} / \mathrm{L})$. As placas foram incubadas a $37^{\circ} \mathrm{C}$ por $72 \mathrm{~h}$. As leveduras foram fenotipicamente caracterizadas através de teste padrão (RICHARD et al., 1980; KREGER-VAN RIJ, 1984; BARNETT et al., 1990). Apenas as leveduras do gênero Candida foram utilizadas no presente estudo. Depois de identificadas, um isolado de cada placa foi mantido em ágar Sabouraud Dextrose a temperatura ambiente. Entre as amostras de leite, cinqüenta e cinco amostras foram positivas para o gênero Candida (12,8\%), entre elas Candida krusei (19 isolados), C. parapsilosis (14 isolados), C. tropicalis (10 isolados), C. albicans (7 isolados), $C$ glabrata (2 isolados), $C$ spp. (2 isolados) e C. rugosa (1 isolado).

\section{Tratamento térmico}

Quarenta e cinco isolados do gênero Candida foram aleatoriamente selecionados, sendo incluídos representantes de todas as espécies identificadas. $\mathrm{Na}$ sequiência as culturas foram analisadas utilizando a metodologia descrita por MELVILLE et al. (1999) e RUZ-PERES et al. (2010). Para todas as avaliações, foram usadas culturas recentes (48h) de leveduras cultivadas em ágar Sabouraud Dextrose. Para cada um dos isolados, a concentração de células em 5,0 mL de Solução salina estéril $(0,85 \%)$ foi ajustada a uma turbidez equivalente ao tubo número 3 da escala de $\mathrm{Mc}$ Farland $\left(9 \times 10^{8} \mathrm{cel} / \mathrm{mL}\right)$. Posteriormente, uma alíquota de $2 \mathrm{~mL}$ de cada suspensão do microrganismo foi transferida para um tubo de vidro estéril contendo 18 $\mathrm{mL}$ de leite integral estéril, que significa uma diluição da ordem de $10^{-1}$ (correspondente a solução mãe/controle com aproximadamente $9 \times 10^{7} \mathrm{cel} / \mathrm{mL}$ ). Após homogeneização $1 \mathrm{~mL}$ de cada suspensão foi distribuído em 15 tubos de vidro estéreis. As amostras foram submetidas a diferentes tratamentos térmicos, cinco tubos a $62-65^{\circ} \mathrm{C}$ por 30 minutos (pasteurização lenta), cinco tubos a $72-75^{\circ} \mathrm{C}$ por 20 segundos (pasteurização rápida), cinco tubos até atingir a fervura, na sequiência todos os tubos foram colocados imediatamente em um banho de gelo.

Após a realização dos três tratamentos térmicos, foram colhidas alíquotas de $0,1 \mathrm{~mL}$ das suspensões testadas (inclusive da solução mãe/controle), as quais foram plaqueadas em ágar Sabouraud Dextrose utilizando-se a técnica de spread plate, e incubadas a $37^{\circ} \mathrm{C}$ por 48 horas, para a avaliação da presença e quantidade de unidades formadoras de colônias de Candida. Os testes que visaram à avaliação da resistência de cada isolado foram repetidos por cinco vezes para cada tratamento térmico. $\mathrm{O}$ isolado foi considerado resistente quando foi observada ausência total de crescimento de colônias em pelo menos três dos cinco testes realizados. 


\section{RESULTADOS}

Em relação aos isolados de leveduras, 6,6\%, $64,4 \%$ e $15,5 \%$ foram resistentes à pasteurização lenta, pasteurização rápida e fervura respectivamente (Tabela1), portanto a pasteurização rápida $\left(72-75^{\circ} \mathrm{C} /\right.$ $20 \mathrm{seg}$ ) foi o método menos eficiente de eliminação das leveduras. Foi observado também que a média de número de colônias recuperadas após os diferentes tratamentos térmicos foi maior para a pasteurização rápida (Tabela 2). No presente estudo, apenas um isolado o número 6 (C. krusei) se mostrou resistente aos três tratamentos utilizados.

\section{DISCUSSÃO}

A eliminação de microorganismos nocivos para os seres humanos é altamente desejável e a pasteurização é o principal processo atualmente utilizado. Diferentes autores descreveram o isolamento de leveduras, especialmente várias espécies de Candida em produtos lácteos (CORBO et al., 2001; SPANAMBERG et al, 2004). .Considerando que os animais podem ser vetores de transmissão ou reservatórios de estirpes que causam doença em humanos e podem representar um risco para os pacientes imuno-comprometidos (EDELMAN et al.,
2005), deve ser dada uma atenção especial aos produtos lácteos, uma vez que conforme os resultados apresentados neste trabalho e no trabalho de RUZPERES et al (2010), isolados de diferentes espécies de Candida se mostraram resistentes aos tratamentos térmicos utilizados, permanecendo viáveis no leite e nos seus derivados.

Embora $C$. albicans continue a ser a causa mais frequiente de fungemia, uma série de relatos tem documentado infecções causadas por $C$. tropicalis, $C$. glabrata, C. parapsilosis, C. krusei e C. lusitaniae (RODRIGUES et al, 2010). O consumo de leite contaminado com Candida representa um dos meios de transmissão, neste sentido NEDRET KOÇ et al. (2001) relataram 12 casos de fungemia por $C$. glabrata que ocorreram entre as crianças internadas em um hospital da Turquia, devido a contaminação do leite.

A resistência de isolados de Candida ao tratamento térmico representa uma dificuldade na eliminação deste patógeno, o que pode representar um risco potencial para a saúde pública.

\section{AGRADECIMENTOS}

Os autores agradecem a Dra. Maria da Graça Portantiolo Corrêa e o Laboratório VITAFORT Ltda pelas amostras de leite mastítico disponibilizadas.

Tabela 1 - Número absoluto e porcentagem da resistência de 45 culturas de Candida, isoladas do leite de bovinos com mastite, provenientes de propriedades leiteiras de quatro estados brasileiros em 2009, frente a diferentes tratamentos térmicos.

\begin{tabular}{ccccccc}
\hline \multicolumn{7}{c}{ Pasteurização } \\
\hline Levedura & $\begin{array}{c}\text { Lenta } \\
\left(62-65^{\circ} \mathrm{C} / 30 \text { min. }\right)\end{array}$ & \multicolumn{2}{c}{$\begin{array}{c}\text { Rápida } \\
\left(72-75^{\circ} \mathrm{C} / 20 \text { seg. }\right)\end{array}$} & & Fervura \\
& $\mathrm{N}$ & $\%$ & $\mathrm{~N}$ & $\%$ & $\mathrm{~N}$ & $\%$ \\
\hline Candida $(\mathrm{n}=45)$ & 3 & 6,6 & 29 & 64,4 & 7 & 15,5 \\
& & & &
\end{tabular}

N- Número absoluto; \% porcentagem

Tabela 2 - Número médio de crescimento de colônias de 45 culturas de Candida isoladas do leite de bovinos apresentando mastite, coletados em quatro estados brasileiros em 2009, e submetidos a diferentes tratamentos térmicos.

\begin{tabular}{cc}
\hline Tratamento térmico & Número médio de colônias \\
\hline Pasteurização lenta $\left(62-65^{\circ} \mathrm{C} / 30 \mathrm{~min}.\right)$ & $0,15^{*}$ \\
Pasteurização rápida $\left(72-75^{\circ} \mathrm{C} / 20 \mathrm{seg}\right)$ & 413,72 \\
Fervura $\left(100^{\circ} \mathrm{C} / 1-3 \mathrm{seg}\right)$ & 3,54 \\
\hline
\end{tabular}

* Numero correspondente a média de colônias crescendo em placas após o respectivo tratamento térmico.

\section{REFERÊNCIAS}

BARNETT, J. A.; PAYNE, R. W.; YARROW, D. Yeast: Characteristics and Identification, 2 ed. Cambridge University Press, 1990.

BRADLEY, A. J. Bovine mastitis: an evolving disease. Veterinary Journal, v.164, p.116-128, 2002.
CORBO, M. R.; LANCIOTTI, R.; ALBENZIO, M.; SINIGAGLIA, M. Occurrence and characterization of yeasts isolated from milks and dairy products of Apulia region. International Journal of Food Microbiology, v. 69, p.146-152, 2001.

EDELMAN, A.; KRUGER, M.; SCHMID, J. Genetic relationship between human and animal isolates of 
Candida albicans. Journal of Clinical Microbiology, v.43, p.6164-6166, 2005.

KIRK, J. H.; BARTLETT, P. C. Bovine mycotic mastitis. Compendium of Food Animal, v.8, p.106110, 1986.

KOUSTA, M.; MATARAGAS, M.; SKANDAMIS, P.; DROSINOS, $\mathrm{H}$. Prevalence and sources of cheese contamination with pathogens at farm and processing levels. Food Control, v.21, p.805-815, 2010.

KREGER-VAN RIJ, N. J. W. The yeast: A Taxonomic Study, Amsterdam: Elsevier (Ed.), 1984, p.1082.

KRUKOWSKI, H.; LISOWSKI, A.; ROZANSKI, P.; SKORKA, A. Yeasts and algae isolated from cows with mastitis in the South-eastern part of Poland. Polish Journal of Veterinary Science, v.9, p.181-184, 2006.

MELVILLE, P. A.; WATANABE, E. T.; BENITES, N. R.; RIBEIRO, A. R.; BUENO, J. A.; GARINO, F.; COSTA, E. O..Evaluation of the susceptibility of Prototheca zopfii to pasteurization of milk. Mycopathologia, v.146, p.83-89, 1999.

NEDRET KOÇ, A; KOCAGOZ, S.; ERDEM, F.; GUNDUZ, Z. Outbreak of nosocomial fungemia caused by Candida glabrata. Mycoses, v.45, p.470475, 2002.

RICHARD, J. L.; MACDONALD, J. S.; FICHTER, R. E.; ANDERSON, A. J. Identification of yeasts from infected bovine mammary glands and their experimental infectivity in cattle. American Journal of Veterinary Research, v.12, p.1991-1994, 1980.
RODRIGUES, D.; ALMIRANTE, B.; CUENCAESTRELLA, M.; RODRIGUEZ-TUDELA, J. L.; MENSA, J.; AYATS, J.; SANCHES, F.; PAHISSA, A. and the BARCELONA CANDIDEMIA PROJECT STUDY GROUP. Predictors of candidemia caused by non-albicans Candida species: results of a populationbased surveillance in Barcelona, Spain. Clinical Microbiology and Infection, v.16, p.1676-1682, 2010.

RUZ-PERES, M.; BENITES, N. R.; YOKOYA, E.; MELVILLE, P. A. Resistência de fungos filamentosos e leveduras isolados de leite cru bovino a pasteurização e fervura. Veterinária e Zootecnia, v.17, p.62-70, 2010.

SEKER, E. Identification of Candida species isolated from bovine mastitic milk and their in vitro hemolytic activity in Western Turkey. Mycopathologia, v.169, p.303-308, 2010.

SPANAMBERG, A.; HARTFELDER, C.; FUENTEFRIA, A. M.; VALENTE, P. Diversity and enzyme production by yeasts isolated from raw milk in Southern Brazil. Acta Scientiae Veterinaire, v.32, p.195-199, 2004.

SPANAMBERG, A.; SANCHES, E. M. C.; SANTURIO, J. M.; FERREIRO, F. Mastite micótica em ruminantes causada por leveduras. Ciência Rural, v.39, p.282-290, 2009.

WATTS, J. L. Etiological agents of bovine mastitis. Veterinary Microbiology, v.16, p.41-66, 1988.

ZHOU, Y.; REN, Y.; FAN, C.; SHAO, H.; ZHANG, Z.; MAO, W.; WEI, C.; NI, H.; ZHU, Z.; HOU, X.; PIAO, F.; CUI, Y. Survey of mycotic mastitis in dairy cows from Heilongjiang Province, China. Tropical Animal Health and Production, DOI 10.1007/s1250013-0419-y. 